Brown, S.S., Forrest, J.A.H. \& Roscoe, P. (1972) A controlled trial of fructose in the treatment of acute alcoholic intoxication. Lancet, ii, 898.

KAYE, S. \& HAAG, H.B. (1957) Terminal blood alcohol concentrations in ninety-four fatal cases of acute alcoholism. Journal of the American Medical Association, 165, 451.

LAURIE, W. (1971) Alcohol as a cause of sudden unexpected death. Medical Journal of Australia, 1, 1224.

Patel, A.R., Paton, A.M., Rowan, T., Lawson, D.H. \& Linton, A.L. (1969) Clinical studies on the effect of laevulose on the rate of metabolism of ethyl alcohol. Scottish Medical Journal, 14, 268.

SCHREINER, G.E. (1958) The role of haemodialysis (artificial kidney) in acute poisoning. Archives of Internal Medicine, 102, 896.
Sodeman, W.E. \& Sodeman, W.E., JR (1967) Pathologic Physiology. W. B. Saunders, Philadelphia and London, p. 106.

Walder, A.I., Reddings, J.S., Faillace, L., Steenburg, R.W. (1969) Rapid de-toxification of the acute alcoholic with haemodialysis. Surgery, 66, 201.

Walls, H.J. \& Brownlie, A.R. (1970a) Drink, Drugs and Driving. Sweet and Maxwell, London, p. 38.

Walls, H.J. \& Brownlie, A.R. (1970b) Drink, Drugs and Driving. Sweet and Maxwell, London, p. 17.

Yacoub, M., Mobena, H., Faure, J. \& Mallion, J.M. (1973) Évolution de l'alcoolémie après ingestion massive d'alcool. Bulletin Médical Légal et Toxicologique, 16, No. 6, 447.

\title{
Coma following treatment of very severe arterial hypertension, with improvement after dexamethasone therapy
}

\author{
L. J. FARROW \\ M.D., M.R.C.P.
}

\author{
J. B. WoOD \\ B.M., M.R.C.P.
}

Division of Medicine, St Mary's Hospital, London W.2

\section{Summary}

We describe two patients with very severe arterial hypertension, who were treated vigorously and effectively with hypotensive drugs. Both promptly developed gross neurological abnormalities, yet recovered fully after treatment with dexamethasone. We have found no similar published reports. We believe that these cases illustrate an important risk of treatment of severe hypertension, and we suggest that cerebral oedema developed, and was then relieved by dexamethasone.

\section{Introduction}

The autoregulation of the cerebral circulation results in a constant cerebral blood flow despite wide fluctuations in arterial pressure. At very high pressure this autoregulation is overwhelmed and cerebral blood flow increases, and at very low pressures autoregulation fails and blood flow diminishes (Strandgaard et al., 1973). In arterial hypertension, autoregulation persists, but functions over a higher range of blood pressures than normal. In a group of severely hypertensive patients, Strandgaard et al. (1973) showed that autoregulation broke down when the mean arterial pressure fell abruptly to $120 \mathrm{mmHg}$,

Requests for reprints: Dr J. B. Wood, County Hospital, Hereford HR1 2ER. and dizziness due to cerebral hypoxia occurred when the mean arterial pressure fell to about $70 \mathrm{mmHg}$, in contrast to normotensive subjects who could tolerate much lower pressures. Vigorous treatment of hypertension may, therefore, lead to cerebral hypoxia if the blood pressure falls too far. Fazekas (1966) recommended that the diastolic pressure should only be brought rapidly to $110 \mathrm{mmHg}$, and that further reduction should be gradual to allow time for the cerebral circulation to adjust to the lower pressure. Most articles and textbooks do not give specific advice about this, or describe what happens if treatment is too effective.

\section{Case 1}

A 44-year-old West Indian woman had a 2-year history of very severe untreated hypertension of unknown cause, and developed headache, drowsiness and left-sided weakness. Gross papilloedema, Cheyne-Stokes respiration and blood pressure of $230 / 160 \mathrm{mmHg}$ were found. She was treated with pentolinium, guanethidine, diazoxide and intravenous mannitol, and her diastolic pressure fell to between 70 and $110 \mathrm{mmHg}$. Within $12 \mathrm{hr}$ she became drowsy, with weakness of the right arm and face, and then became comatose, with fixed dilated pupils, a stiff neck and fresh retinal haemorrhages. 
Dexamethasone, $12 \mathrm{mg}$, was given intravenously, followed by $5 \mathrm{mg}$ 6-hourly. Within $12 \mathrm{hr}$ she had improved, in $36 \mathrm{hr}$ was conscious and her abnormal signs disappeared. Dexamethasone was continued for 10 days and she was discharged in 3 weeks.

She stopped treatment and 3 months later collapsed at home. Gross papilloedema and a diastolic pressure of $205 \mathrm{mmHg}$ were found and she died. At post mortem there was moderate atheroma of the vertebro-basilar system and a small old infarct in the right side of the pons. No cause for the hypertension was found.

\section{Case 2}

A 50-year-old English woman had hypertension for 6 months which had not been treated. She developed severe headache, vomiting and pallor. On examination she was anxious with a slight tremor, but was alert, intelligent and sensible. Blood pressure was $300 / 190 \mathrm{mmHg}$ and papilloedema was present. She was treated with pentolinium and the blood pressure fell over $4 \mathrm{hr}$ from $270 / 170$ to $150 / 100$ $\mathrm{mmHg}$. She became drowsy, but obeyed simple commands. During the next 2 days the blood pressure was held between 200/140 and 150/90 (see Fig. 1) and she became progressively more drowsy. She developed athetoid movements of hands and

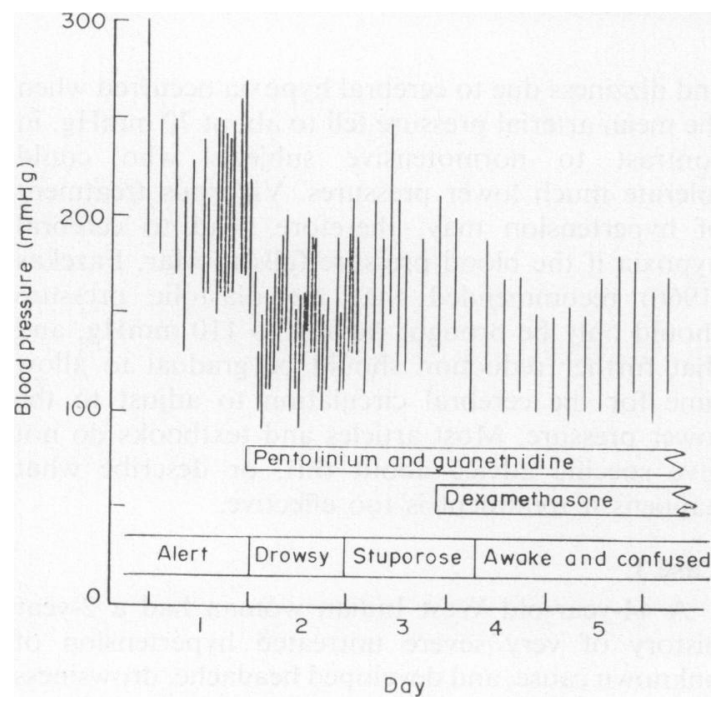

FIG. 1. Changes in blood pressure and mental state during treatment-Case 2.

legs, neck stiffness, an intermittent Babinsky response on the right, and she adopted a position with flexed arms and extended legs which suggested decerebrate rigidity. Her plasma sodium and potassium fell to 119 and $3.3 \mathrm{mEq} / \mathrm{l}$ respectively. At this stage she was deteriorating and was given $260 \mathrm{mmol}$ of sodium chloride intravenously and dexamethasone $4 \mathrm{mg}$ 6-hourly. Within $12 \mathrm{hr}$ she responded to commands and stopped her athetoid movements, but remained confused. Examination of cerebro-spinal fluid 4 days later was normal. Her mental state slowly improved and 4 months later she returned to work. Dexamethasone was given for 16 days and blood pressure was controlled by guanethidine and propranolol. No cause for the hypertension was found.

\section{Discussion}

In both patients severe mental deterioration occurred soon after reduction of blood pressure. On the first day of treatment the mean arterial pressure did not fall below $100 \mathrm{mmHg}$ in either patient. At this level Strandgaard et al. (1973) and Finnerty et al. (1954) found no clinical signs of hypoxia in their hypertensive subjects. However, our patients' mean pressures were sometimes below $120 \mathrm{mmHg}$, which was the level at which Strandgaard et al. (1973) found that autoregulation began to fail in their severely hypertensive subjects. As both our patients had exceptionally severe untreated hypertension, it is probable that their autoregulatory mechanisms were adjusted to function at even higher levels than the subjects of Strandgaard et al. (1973) and Finnerty et al. (1954). We suggest that this maladjustment o autoregulation made our patients particularly liables to develop cerebral hypoxia when the blood pressure fell. Both patients developed confusion, neck stiffness and had headaches, but lumbar puncture in one and eventual autopsy in the other showed no evidence of subarachnoid haemorrhage. We attribute the confusion, coma, stiff neck and other signs to the effects of hypoxia.

Hypoxia causes cerebral oedema, and so does severe hypertension (Byrom, 1954). Thus it seems probable that oedema was present when these patients were most ill. Dexamethasone relieves cerebral oedema from many causes, and the improvement and eventual recovery which followed its use is consistent with the hypothesis that cerebral oedema was present.

These case histories support the recommendation of Fazekas (1966) that initial treatment of severe hypertension should not bring the diastolic pressure below $110 \mathrm{mmHg}$, but this advice may not be cautious enough in patients with very severe longstanding hypertension, since patient 2 deteriorated despite a diastolic pressure at or above $110 \mathrm{mmHg}$ for most of the first 3 days of treatment.

If neurological deterioration follows reduction of blood pressure, we strongly recommend a trial of dexamethasone to treat the cerebral oedema which is probably present. Improvement occurred within $12 \mathrm{hr}$ in our patients, the drug caused no adverse effects, and was later stopped without difficulty. 


\section{Acknowledgments}

We wish to thank Dr C. A. Young, Dr J. W. Litchfield and Dr R. D. Green for permission to describe these cases, and we wish to thank Professor W. S. Peart for his encouragement.

\section{References}

Byrom, F.B. (1954) The pathogenesis of hypertensive encephalopathy and its relation to the malignant phase of hypertension. Lancet, ii, 201.
FAZEKAS, J.F. (1966) Cerebrovascular consequences of hypertension-therapeutic complications. American Journal of Cardiology, 17, 608.

Finnerty, F.A., Witkin, L., Fazekas, J.F., Langbart, M. \& YounG, W.K. (1954) Cerebral hemodynamics during cerebral ischaemia induced by acute hypotension. Journal of clinical Investigation, 33, 1227.

StrandgaArd, S., Olesen, J., SkinhoJ, E. \& Lassen, N.A. (1973) Autoregulation of brain circulation in severe arterial hypertension. British Medical Journal, 1, 507.

\section{Carbon monoxide poisoning: recovery associated with a transient dyskinetic syndrome}

\author{
J. A. Sills \\ M.R.C.P., D.C.H.
}

\author{
ELENA VIVORI \\ F.F.A., R.C.S.
}

\section{ROSENBLOOM \\ M.R.C.P., D.C.H.}

\section{Royal Liverpool Children's Hospital, Liverpool L7 7DG}

\begin{abstract}
Although exposure to fire on domestic premises is increasingly hazardous because of the fumes produced by burning synthetic substances used in furnishings and other materials, one of the principal dangers to individuals trapped by fire continues to be poisoning by carbon monoxide. This case report illustrates the potentially severe nature of this variety of asphyxia. An account is given of the measures used in resuscitation and of the evolution of the patient's clinical condition.
\end{abstract}

\section{Case report}

The patient, a boy aged 8 years, was trapped by smoke in a house fire and subsequently rescued by firemen wearing breathing apparatus. His younger brother aged 6 years was similarly trapped and rescued but was adversely affected only to the extent of suffering fairly marked inspiratory stridor. The older boy was more seriously affected and in spite of attempted resuscitation had no spontaneous respiration on arrival at the casualty department of the Royal Liverpool Children's Hospital.

Resuscitative measures thereafter included immediate intubation and ventilation with $100 \%$ oxygen, correction of acidosis, intravenous hydrocortisone and bronchial lavage with normal saline. Shortly after admission a brief episode of decerebrate rigidity occurred and $50 \mathrm{ml}$ of $10 \%$ mannitol was given intravenously in an attempt to reverse any cerebral oedema. Two hours after admission the child's carboxyhaemoglobin level was greater than $80 \%$ and by extrapolation it was assumed to have been considerably higher at the time of admission. At this stage $200 \mathrm{ml}$ of blood was transfused in order to increase blood oxygen carrying capacity. Curarization and mechanical ventilation with $100 \%$ oxygen (in order to decrease the respiratory efforts and the oxygen needs of the patient) were continued. Carboxyhaemoglobin level $9 \mathrm{hr}$ after admission was $10 \%$ and the $100 \%$ oxygen used up to then was reduced to $40 \%$ oxygen in air.

On the following day the child, in the twilight periods between sedation and curarization, was able to obey simple commands. Extubation was possible after $72 \mathrm{hr}$ although sedation had to be continued for a further $48 \mathrm{hr}$ as he became stridulous when agitated. Seven days after admission cognitive function appeared to have fully recovered, but abnormal motor function with dysarthria, athetosis predominantly of the face and upper limbs, and a spastic diplegia predominantly affecting the lower limbs was present. After $24 \mathrm{hr}$ of these distressing symptoms dexamethasone therapy was instituted, and coincidentally the dyskinesia began slowly to resolve. 